\title{
Removal of contaminants of emerging concern (CECs) using a membrane bioreactor (MBR): a short review
}

\author{
Kwon Y. and Lee D.G.* \\ Korea \\ Received: 12/07/2018, Accepted: 06/04/2019, Available online: 10/04/2019 \\ *to whom all correspondence should be addressed: e-mail: dlee31@inu.ac.kr \\ https://doi.org/10.30955/gnj.002823
}

Department of Environmental Engineering, Incheon National University, 119 Academy-ro, Yeonsu-gu, Incheon, 22012, Republic of

\section{Abstract}

Contaminants of emerging concern (CECs), such as pharmaceuticals and personal care products (PPCPs) and as endocrine disrupting compounds, have recently recognized as the next set of pollutants due to their toxic effects on human health and aquatic organisms at very low concentrations. One of effective methods to remove these emerging contaminants present in the aquatic environment is a membrane bioreactor (MBR). In this review, 27 CECs belonged to diverse categories of PPCPs were surveyed from the point of view of the removal efficiency by several types of MBR modules with various operational conditions, such as a type of MBR, hydraulic retention time and sludge retention time. As a result, this review provided the overall ranges in the removal efficiency of 27 CECs by different MBR filtrations and modules. Certain categories of PPCPs such as analgesics/anti-inflammatory drugs (acetaminophen and ibuprofen), steroids/hormones (estriol and testosterone) and stimulant (caffeine) have relatively higher removal rates, while antimicrobial agent (TCEP) is rarely removed in the different MBRs. For further implementation of CEC removal by a MBR system, physical characteristics/biological fate of a wide variety of CECs, individual/synergistic effects which may occur during MBR operation, and application of advanced MBR technologies should be studied.

Keywords: Wastewater treatment, pharmaceuticals and personal care products (PPCPs), removal efficiency.

\section{Introduction}

Many studies have reported that novel organic compounds synthesized for various purposes, such as personal care (i.e. hand soap, sunscreen, shampoo and cosmetics etc.), agricultural activities, and human/animal health care, can threaten aquatic ecosystem (Lapworth et al., 2012; Jiang et al., 2013; Liu et al., 2013). Due to the advancement of medical science, therapeutic compounds such as aspirin, arsphenamine and ephedrine, have been developed in early $20^{\text {th }}$ and widely used as pain relievers and medicines against different types of illness (Tiwari et al., 2016). A large consumption of these personal care products and pharmaceuticals (PPCPs) eventually contributes organisms in the aquatic environment to be exposed by contaminants of emerging concern (CECS). CECs are manmade pollutants and still remained less significant than their potential impacts due to the detection of these chemicals at infinitesimal concentrations; from $\mu \mathrm{g} / \mathrm{L}$ to $\mathrm{ng} / \mathrm{L}$ across an array of ecosystems. Recently, environmental scientists have dealt with the occurrence of CECs in surface water, water supply, wastewater, groundwater and sewage sludge in various regions including European, Asian, American and even African communities (Jiang et al., 2013; Guo et al., 2014; Subedi et al., 2015; Hashim et al., 2016; Fisch et al., 2017; Fisch et al., 2017; Krogh et al., 2017; Kwon et al., 2017).

One convincing technology to treat emerging contaminants including PPCPs in municipal wastewater treatment plants (WWTPs) is a membrane filtration with reverse osmosis (RO), nano-filtration (NF), ultra-filtration (UF) or micro-filtration (MF) (Kim et al., 2007). Membranes are thin and permeable layers of material that can be used to remove contaminants in water by permitting the transmission of water at a different rate according to the porous size of the membrane (Visvanathan et al., 2000; Benjamin et al., 2013). As the technology of membrane filtration has been dramatically advanced, environmental scientists have made attempts to combine microporous or nanoporous membranes with the conventional activated sludge (CAS) system for solid and liquid separation, instead of using the secondary clarifiers (Shariati et al., 2010; Chon et al., 2011; Benjamin et al., 2013). More recently, various integrated MBR modules, for example, advanced oxidation process combined with electrocoagulation MBR, reverse osmosis MBR (RO-MBR), forward osmosis MBR (FO-MBR), membrane distillation bioreactor (MDBR), biofilm/bioentrapped MBR and granular MBR, have been developed to circumvent limitations of conventional MBRs (Neoh et al., 2016). Eventually, this innovative technology have led to increase the removal efficiency of suspended solids, organic micropollutants and even CECs (Tan et al., 2017). 
For those reasons, extensive studies have reported the removal of CECs by different MBR system and modules (Kim et al., 2007; Radjenovic et al., 2007; Radjenović et al., 2009; Chon et al., 2011; Tiwari et al., 2016). For instance, Kim et al. (2007) surveyed the occurrence of PPCPs in surface water, drinking water and wastewater in South Korea and measured the elimination efficiency using the RO and NF MBRs. Radjenovic et al. (2007) demonstrated that the MBR was more effective (removal rate $>80 \%$ ) to treat the certain pharmaceuticals than the conventional activate sludge (CAS) system. Further, Radjenović et al. (2009) reported the better removal of pharmaceutically active compounds (PhACs), such as mefenamic acid, diclofenac and indomethacin, which were properly removed by CAS process.

The primary objective of this review is to compare the performances of an array of MBR modules with various operational conditions, and to evaluate the results from a wide range of the reported MBR studies in terms of removal efficiency of PPCPs belonged to CECs. The PPCPS evaluated in this review were included in analgesics/antiinflammatory drugs, antibiotics, antiepileptic drug, $\beta$-blockers, blood lipid regulators, steroids/hormones (estriol and testosterone), stimulant, antimicrobial agent/disinfectant, flame retardant, and synthetic musks/fragrances. Therefore, providing information on overall removal rates with relatively well-/rarely removed PPCPs by MBR operational condition would be useful as a criterion for treatment strategy to effectively manage wastewater systems as well as to improve the sustainability of aquatic environment.

\section{Membrane bioreactor}

\subsection{Classification of $M B R$}

Membranes are generally divided into several groups according to the type of membrane and the application. Membranes are commonly classified as reverse osmosis (RO), nano-filtration (NF), ultra-filtration (UF), micro-filtration (MF) and particle-filtration regarding to the permeability of contaminants through the thin layers of the membrane (Benjamin et al., 2013; Yoon, 2015). As the maximum pore dimensions of the membrane decrease, the permeability of contaminants through membrane usually decreases (Nath, 2017). Dead-end and the circular cross-flow filtration are two important types of filtration that should be considered. In dead-end filtration, the input flow runs perpendicular to the membrane whereas in cross-flow filtration, the input flow is parallel to the membrane (Shamsuddin et al., 2015). The membrane configurations most widely used are hollow fiber and flat sheet module. The typical arrangement of a membrane bioreactor is represented as a submerged $\mathrm{MBR}$, but a side-stream $\mathrm{MBR}$ is an alternative (Nath, 2017).

The material of the membrane usually can be polymeric, metallic or ceramic (Lin et al., 2013). Polymeric membranes are made of a polymer monolith such as polyvinylidene difluoride (PVDF), polyethylene (PE), polypropylene and polyethersulfone (PES) which is the most broadly applied (Lin et al., 2013). Moreover, polymeric membranes have the characteristics of being a single material, being self-supporting and being the only material used to construct hollow fiber membranes (Lee et al., 2013). Metallic membranes have advanced hydraulic performance and fouling recovery. In addition, metallic membranes have more durable tolerance especially to high temperature and oxidation in comparison with polymeric membrane material (Kim et al., 2007). Ceramic membranes is one of the most widely used material particularly for anaerobic MBR (AnMBR) system (Imasaka et al., 1989; Chang et al., 1994; Ghyoot et al., 1997), due to their effective resistance to corrosion, abrasion, increased concentration polarization control, and fouling through backwashing (Ersu et al., 2008). Ceramic membranes are needed to be supported with multiple materials and can be used for either hollow fiber or flat sheet configuration (Kumar et al., 2015). However, as metallic membranes and ceramic membranes are much more expensive than polymeric membrane materials, there is limitation on the large scale implementation (Kumar et al., 2015). Polymeric membranes are more economical for commercial applications (Lin et al., 2013).

\subsection{The characteristics of membrane bioreactor (MBR)}

The membrane bioreactor (MBR) has three main advantages: 1) the water quality treated by a MBR is independent of the mixed liquor suspended solids (MLSS) (Yoon, 2015); 2) a secondary clarifier and a tertiary process are not necessary in the MBR system, because the MBR plays the important role of clarifier that is similar to a conventional activated sludge (CAS) system, thus the overall size of MBR plant can be significantly reduced (Howell, 2004; Shariati et al., 2010); 3) a longer sludge retention time (SRT) allowed a MBR process to provide 2 to 5 times more active biomass than a CAS system, thus effluent water quality in a MBR system is considerably higher than that from a CAS process (Yamamoto et al., 1989; Jefferson et al., 2000). At the same time, the longer SRT improved active biological degradation due to the increased sludge concentration (Marrot et al., 2004). However, the most significant concern is fouling during the operation of a MBR system. Fouling in a MBR system indicates that the accumulation of rejected materials on a membrane increases the resistance to transporting water through the membrane layers (Marrot et al., 2004). Fouling can be controlled either physically or chemically, i.e. by backwashing with air and/or water, or by using chemicals like caustic soda, and oxidants including hydrogen peroxide (Shen et al., 2015; Yoon, 2015). The performance of MBR process can be determined by several operating parameters. Hai et al. (2011) reported that the level of total organic carbon (TOC) and total nitrogen (TN) have significantly reduced at $45{ }^{\circ} \mathrm{C}$ rather than the temperature range of $10{ }^{\circ} \mathrm{C}$ to $35{ }^{\circ} \mathrm{C}$ in the bioreactor. Some PPCPs like acetaminophen, ketoprofen, naproxen, roxithromycin, sulfamethoxazole and trimethoprim have higher removal efficiency in the longer SRT (= 30-day) compare to 15-day of SRT (Tambosi et al., 2010). 


\section{Contaminants of emerging concern (CECs) treatment in MBR}

\subsection{Contaminants of emerging concern (CECS)}

Contaminants of emerging concern (CECs) can be any chemical compounds including industrial chemicals, persistent organic compounds (POPs), natural toxic compounds, and pharmaceuticals and personal care products (PPCPs). One major category, PPCPs are steadily being found in the aquatic environment at low concentrations, and have recently received significant attention by environmental scientists as well as policy makers (Kumar et al., 2010; Archer et al., 2017).

The general forms of PPCPs consumed by human are medicines, veterinary drugs, and cosmetic products (Sui et al., 2017). The type of PPCPs is usually classified according to their applications. Pharmaceuticals can be analgesics and anti-inflammatory drugs, antibiotics, antiepileptic drugs, blood lipid regulators, B-blocks, stimulant, steroids and hormones (Ellis, 2006). As personal care products (PCPs), antimicrobial agents and disinfectants, artificial sweetener, cosmetics, flame retardants, insect repellants, synthetic musks, fragrances, and sunscreen UV filters have been widely used (Jiang et al., 2013; Liu et al., 2013). Further, PPCPs that can cause endocrine disruption (e.g., estrone (E1), estradiol (E2), testosterone and norgestrel) were described in Table 1.

PPCPs can have adverse effects in both humans and aquatic organisms. Even though the concentrations of PPCPs present in water bodies are as low as parts per trillion, the influence of PPCPs on neurobehavioral effects, inhibition of efflux pumps, and rapid inhibition of sperm activity have been observed (Wilkinson et al., 2016; Yang et al., 2017).

The endocrine system is an integrated system of glands and hormones that governs growth, development, reduction and metabolism (Ying et al., 2004). The major endocrine glands are the pineal gland, the pituitary gland, the thyroid gland, the thymus, the adrenal gland, the pancreas, the ovary (female) and the testes (male) (Ying et al., 2004; Holtz, 2006). EDCs can usually be absorbed into blood through food, skin or air, and disrupt the function of the endocrine glands by directly activating/blocking hormone receptors or by controlling hormone levels or hormone receptor concentrations (Tijani et al., 2016; Archer et al., 2017). The important chemicals of EDCs are pesticides, detergents, plasticizers, and a mixtures of unknown EDCs in wastewater (Dotan et al., 2016). The most well-known examples of EDCs include dioxins, polychlorinated biphenyls (PCBs), dichlorodiphenyl trichloroethane (DDT), di- $n$-butylphthalate, bisphenol and diethylstilbestrol (DES), a synthetic estrogen (Giulivo et al., 2016). The PCBs and dioxins cause immune alterations while dioxins and DDT result in diabetes and precocious puberty, respectively (Eskenazi et al., 2017).
3.2. Pathway to aquatic environment and human effects of CECS

The occurrence of CECs including pharmaceutically active chemicals and endocrine disrupting compounds in the domestic and industrial wastewater have been recognized as a crucial environmental concern in ecological system (Kasprzyk-Hordern et al., 2009). Gros et al. (2010) reported that over 3,000 different pharmaceuticals were used for human medications within daily human activity in the European Union (EU), resulting in a wide variety of CECs pathways into the aquatic environment (K'oreje et al., 2016; Mandaric et al., 2017).

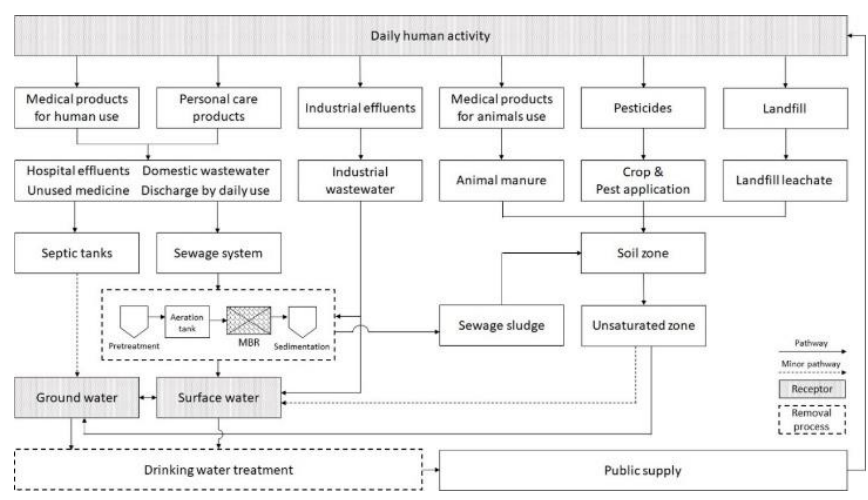

Figure 1. Possible pathways of CECs in the aquatic organisms (adapted from Ellis, 2006 and Stuart et al., 2012)

According to previous studies on occurrence of CECs, discharge of treated water from WWTPs can be one of pathways into the water bodies due to the limited removal of pharmaceuticals by conventional secondary processes and/or sewage treatment plants (STPS) (Jiang et al., 2013; Petrie et al., 2015). Personal care products (PCPs) such as cosmetics, hair care products, tooth pastes and skin care products are also analogous to pharmaceuticals as shown in Figure 1. CECs can be also released from agricultural and rural point source due to the use of pesticides that can adversely affect crops, aquatic and soil ecosystems (Stuart et al., 2012). Consequently, there is no doubt that humans can be potentially exposed to CECs through the unexpected pathways (Lu et al., 2011).

Concerning the human exposure to CECs, the octanolwater partition coefficient $\left(K_{\text {ow }}\right)$ and the solubility in water $\left(S_{w}\right)$ should be considered. While the a target compound with a log $K_{\text {ow }}$ lower than 4 is considered as hydrophilic, that with a log $K_{\text {ow }}$ higher than 4 is hydrophobic (Meffe et al., 2014). Pan et al. (2009) examined that hydrophobic contaminants such as diclofenac ( $\left.\log K_{\text {ow }} 4.51\right)$, estradiol (log $\left.K_{\text {ow }} 4.01\right)$, gemfibrozil (log $\left.K_{\text {ow }} 4.77\right)$ and mefenamic acid (log $K_{\text {ow }} 5.12$ ) generally showed the high sorption affinity particularly onto organic matters. 
Table 1. List of general pharmaceutical and personal care products (Esplugas et al., 2007; Kim et al., 2009; Liu et al., 2013)

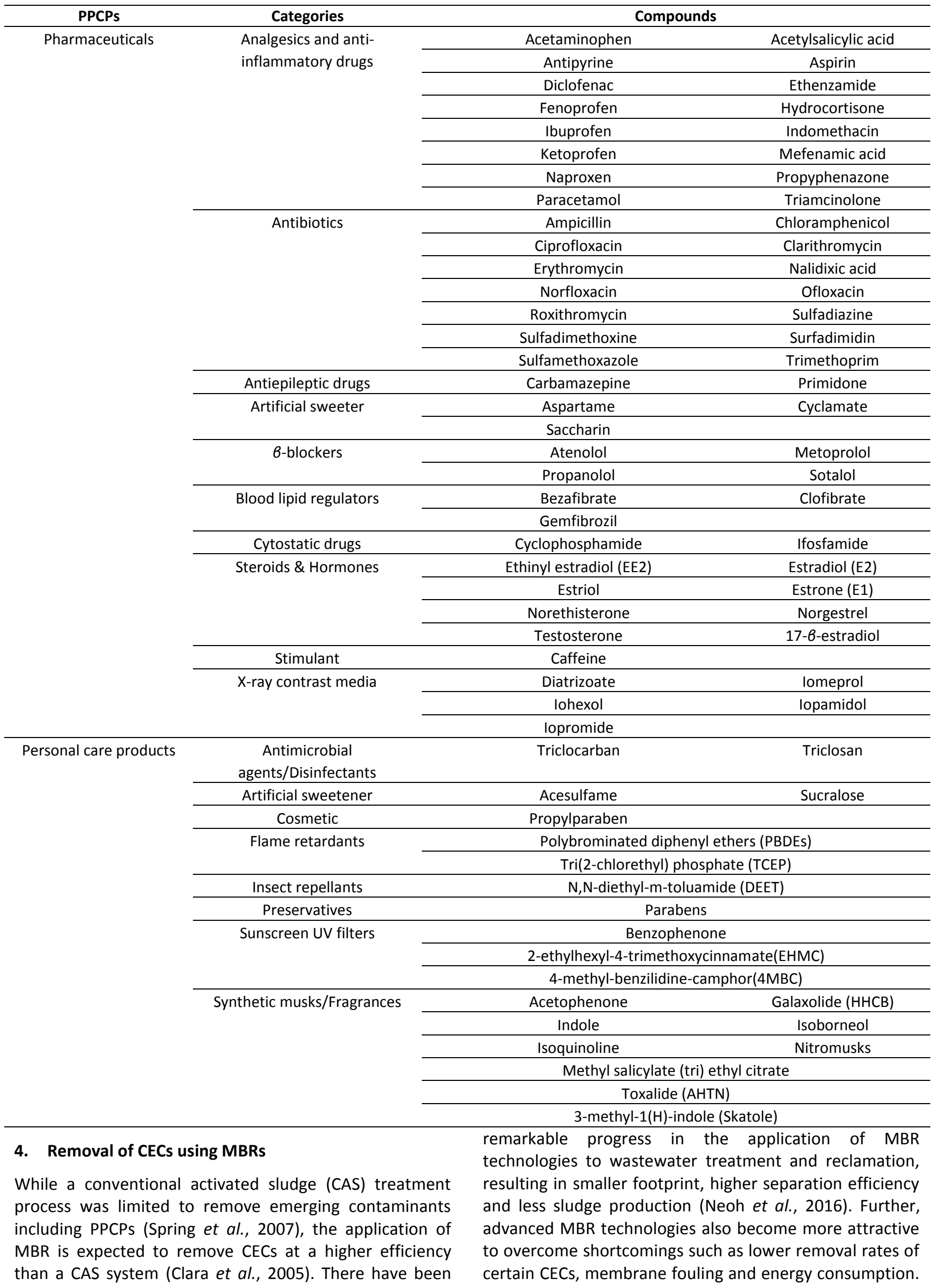


For example, Mascolo et al. (2010) reported that advanced oxidation processes (AOPs) and electrocoagulation processes with MBR provided the higher removal efficiency $(20 \%-60 \%$ higher than conventional MBR) in pharmaceutical wastewater. Hybrid moving bed biofilm reactor-MBR (hybrid MBBR-MBR) contributes to reduce the concentration of suspended solids for membrane fouling mitigation without efficiency loss for treatment by allowing plastic carriers attached with microorganisms to freely move in the bioreactor (Leyva-Díaz et al., 2013). Osmotic MBR has brought several advantages e.g. better water quality production and lower energy consumption. conventional MBR is not able to effectively remove some persistent hydrophilic contaminants, while osmotic membrane bioreactor can retain any micro-organic compounds through longer contact time for biodegradation (Tan et al., 2015). Osmotic MBR can also minimize the use of energy through the osmotic driving force supplied by a draw solution (Wang et al., 2014).

In this study, we reviewed a wide range of CECs removal performance, particularly elimination of PPCPs, using different MBR processes. As a result, the overall removal ranges of 27 CECs (analgesics and anti-inflammatory: acetaminophen, diclofenac, ibuprofen, indomethacin, ketoprofen, mefenamic acid, naproxen, propyphenazone; antibiotics: erythromycin, ofloxacin, roxithromycin, sulfamethoxazole, trimethoprim; antiepileptic drugs: carbamazepine; b-blocks: atenolol, metoprolol, propanolol, sotalol; blood lipid regulators: bezafibrate, gemfibrozil; steroids/hormones: estriol, testosterone; stimulant: caffeine; antimicrobial agent/disinfectant: triclosan; flame retardant: Tri(2-chloroethyl) phosphate (TCEP); synthetic musks/fragrances: galaxolide (HHCB), toxalide (AHTN)) by various MBR operating conditions and filtration have been summarized in Table 2 . Acetaminophen, ibuprofen, estriol and caffeine are the well-treated contaminants (>99\%) regardless of the types of membrane films and modules (e.g. nanofiltration, ultrafiltration, hollow-fiber type and flat-sheet module), hydraulic retention time (HRT) and sludge retention time (SRT). However, indomethacin (13-65\%), mefenamic acid (7.2-74.8\%) and TCEP (0.3\%) are not well-removed or have the comparably huge gap between different elimination rates. Despite of the same contaminant, there are significant differences in the removal efficiency as the treatment method and operation condition. For example, erythromycin, one of antibiotics, was removed about $4.5 \%$ when it was treated by hollow fiber module, whereas it was well-removed (about 90\%) through hollow-fiber module with 12-hr of HRT and 72-day of SRT (Kim et al., 2007; Reif et al., 2008). Radjenović et al. (2009) and Chon et al. (2011) reported that naproxen, used as analgesic and anti-inflammatory drug, was removed over $78 \%$ with micro-filtration and nano-filtration. However, Radjenovic et al. (2007) demonstrated that more than $99 \%$ of naproxen was eliminated using two flat-sheet module with 14-hr of HRTs. Erythromycin and carbamazepine have the wide range in the removal efficiency, $4.5-91.0 \%$ and $4.4-93.0 \%$ respectively. Hence, it is clear that each chemical compound has different optimal condition for effective elimination, despite same MBR configuration and operation is applied. For example, analgesics/antiinflammatory drugs (i.e. acetaminophen and ibuprofen), steroids/hormones (i.e. estriol and testosterone) and stimulant (i.e. caffeine) are relatively well-removed, while antimicrobial agent (TCEP) is difficult to be removed by the MBRs.

Regarding membrane types, micro-filtration, ultrafiltration and nano-filtration were mainly used in the studies we reviewed. In the case of diclofenac, sulfamethoxazole and carbamazepine, the removal efficiency by nano-filtration (97.0\%, 90.0\%, 93.0\% respectively) are generally higher than ultra-filtration MBRs (32.9-50.6\%, 61.4\%, 4.4-12.5\% respectively). However, the increase in removal efficiency of a PPCP are not necessarily correlated with the decrease in pore size (micro>ultra>nano) of membrane types. For instance, the removal efficiencies of naproxen were $87.5-93.9 \%$ (micro-filtration), $83.5 \%$ (ultra-filtration) and $78.0 \%$ (nano-filtration), while atenolol was removed by about 64.1-89.3\%, 57.0-82.0\% and $85.0 \%$ using micro-, ultra- and nano-filtrations, respectively.

SRT can be one of well-known parameters to evaluate the removal efficiency of aquatic contaminants during the treatment process. Tambosi et al. (2010) performed two membrane bioreactor pilot plants to remove highly consumed six pharmaceuticals (acetaminophen, ketoprofen, naproxen, roxithromycin, sulfamethoxazole and trimethoprim), particularly applying two different SRTs of 15-day and 30-day. As a result, higher removal ratios were observed for the longer SRTs due to the longer contact time for biodegradation. The other study showed that adsorption of contaminants into the sludge is directly associated with the sludge concentration in a MBR, since the higher concentration of sludge provides additional adsorption sites to contaminants (Schäfer et al., 2002). For the further study, therefore, evaluation of the CECs removal efficiency according to the type/composition of sludge, and their physical characteristics/biological fate in MBR would be required for a better understanding on the adsorption and biodegradation mechanism of CECs in a MBR system.

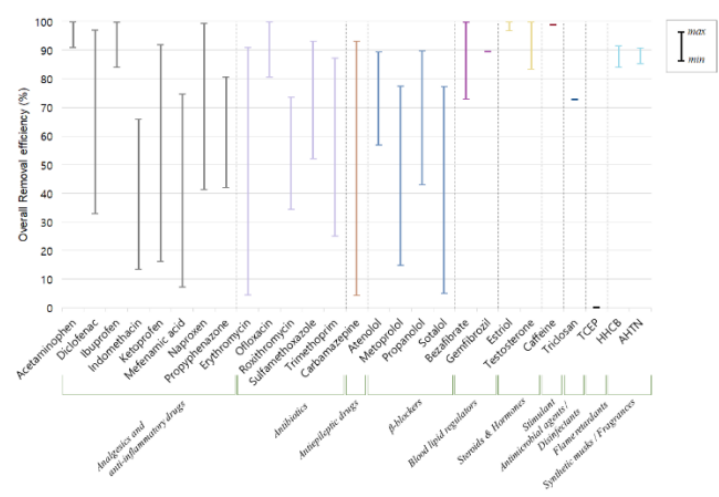

Figure 2. Overall range of removal efficiency applying different kinds of operational condition in MBR technology (summarized from Table 2) 
Table 2. Removal efficiency of PPCPs in various operation condition with MBR systems

\begin{tabular}{|c|c|c|c|c|c|c|}
\hline \multirow[t]{2}{*}{ PPCPs } & \multirow[t]{2}{*}{ Removal \% } & \multicolumn{4}{|c|}{ Operation condition } & \multirow[t]{2}{*}{ Reference } \\
\hline & & $\begin{array}{l}\text { Type of } \\
\text { module }\end{array}$ & MBR filter & HRTs (h) & SRTs (d) & \\
\hline \multicolumn{7}{|c|}{ Pharmaceuticals } \\
\hline \multicolumn{7}{|c|}{ Analgesics and anti-inflammatory drugs } \\
\hline \multirow{5}{*}{ Acetaminophen } & 91.0 & N.A & Nano-filtration & 15.4 & $180 \pm 84.9$ & Chon et al. (2011) \\
\hline & $99.6-99.9$ & Flat-sheet & Micro-filtration & 15 & N.A & Radjenović et al. (2009) \\
\hline & 99.6 & Two flat-sheet & N.A & 14 & Infinite* & Radjenovic et al. (2007) \\
\hline & $99.8-99.9$ & Hollow-fiber & Ultra-filtration & 7.2 & N.A & Radjenović et al. (2009) \\
\hline & $>99.9$ & Hollow-fiber & N.A & N.A & N.A & Kim et al. (2007) \\
\hline \multirow[t]{5}{*}{ Diclofenac } & $32.9-50.6$ & N.A & Ultra-filtration & $12-96$ & $>10$ & Clara et al. (2005) \\
\hline & 97.0 & N.A & Nano-filtration & 15.4 & $180 \pm 84.9$ & Chon et al. (2011) \\
\hline & $52.7-78.9$ & Flat-sheet & Micro-filtration & 15 & N.A & Radjenović et al. (2009) \\
\hline & 87.4 & Two flat-sheet & N.A & 14 & Infinite* & Radjenovic et al. (2007) \\
\hline & $44.3-80.9$ & Hollow-fiber & Ultra-filtration & 7.2 & N.A & Radjenović et al. (2009) \\
\hline \multirow[t]{6}{*}{ Ibuprofen } & $96.9-99.2$ & N.A & Ultra-filtration & $12-96$ & $>10$ & Clara et al. (2005) \\
\hline & $97.4-99.8$ & Flat-sheet & Micro-filtration & 15 & N.A & Radjenović et al. (2009) \\
\hline & 99.8 & Two flat-sheet & N.A & 14 & Infinite* & Radjenovic et al. (2007) \\
\hline & $84.0-98.0$ & Hollow-fiber & N.A & 12 & 72 & Reif et al. (2008) \\
\hline & $97.9-99.8$ & Hollow-fiber & Ultra-filtration & 7.2 & N.A & Radjenović et al. (2009) \\
\hline & 98.3 & Hollow-fiber & N.A & N.A & N.A & Kim et al. (2007) \\
\hline \multirow[t]{3}{*}{ Indomethacin } & $20.8-62.0$ & Flat-sheet & Micro-filtration & 15 & N.A & Radjenović et al. (2009) \\
\hline & 46.6 & Two flat-sheet & N.A & 14 & Infinite* & Radjenovic et al. (2007) \\
\hline & $13.5-65.9$ & Hollow-fiber & Ultra-filtration & 7.2 & N.A & Radjenović et al. (2009) \\
\hline \multirow[t]{3}{*}{ Ketoprofen } & $16.2-71.6$ & Flat-sheet & Micro-filtration & 15 & N.A & Radjenović et al. (2009) \\
\hline & 91.9 & Two flat-sheet & N.A & 14 & Infinite* & Radjenovic et al. (2007) \\
\hline & $23.4-64.3$ & Hollow-fiber & Ultra-filtration & 7.2 & N.A & Radjenović et al. (2009) \\
\hline \multirow[t]{3}{*}{ Mefenamic acid } & $16.8-64.2$ & Flat-sheet & Micro-filtration & 15 & N.A & Radjenović et al. (2009) \\
\hline & 74.8 & Two flat-sheet & N.A & 14 & Infinite* & Radjenovic et al. (2007) \\
\hline & $7.2-63.8$ & Hollow-fiber & Ultra-filtration & 7.2 & N.A & Radjenović et al. (2009) \\
\hline Naproxen & 78.0 & N.A & Nano-filtration & 15.4 & $180 \pm 84.9$ & Chon et al. (2011) \\
\hline & $87.5-93.9$ & Flat-sheet & Micro-filtration & 15 & N.A & Radjenović et al. (2009) \\
\hline & 99.3 & Two flat-sheet & N.A & 14 & Infinite* & Radjenovic et al. (2007) \\
\hline & 83.5 & Hollow-fiber & Ultra-filtration & 7.2 & N.A & Radjenović et al. (2009) \\
\hline & 41.2 & Hollow-fiber & N.A & N.A & N.A & Kim et al. (2007) \\
\hline Propyphenazone & $48.5-80.5$ & Flat-sheet & Micro-filtration & 15 & N.A & Radjenović et al. (2009) \\
\hline & 64.6 & Two flat-sheet & N.A & 14 & Infinite* & Radjenovic et al. (2007) \\
\hline & $42.0-79.4$ & Hollow-fiber & Ultra-filtration & 7.2 & N.A & Radjenović et al. (2009) \\
\hline Antibiotics & & & & & & \\
\hline Erythromycin & 67.3 & Two flat-sheet & & 14 & Infinite* & Radjenovic et al. (2007) \\
\hline & 91.0 & Hollow-fiber & N.A & 12 & 72 & Reif et al. (2008) \\
\hline & 4.5 & Hollow-fiber & N.A & N.A & N.A & Kim et al. (2007) \\
\hline Ofloxacin & $92.4-98.0$ & Flat-sheet & Micro-filtration & 15 & N.A & Radjenović et al. (2009) \\
\hline & $80.5-99.9$ & Hollow-fiber & Ultra-filtration & 7.2 & N.A & Radjenović et al. (2009) \\
\hline Roxithromycin & $34.4-73.5$ & N.A & Ultra-filtration & $12-96$ & $>10$ & Clara et al. (2005) \\
\hline Sulfamethoxazole & 61.4 & N.A & Ultra-filtration & $12-96$ & $>10$ & Clara et al. (2005) \\
\hline & 90.0 & N.A & Nano-filtration & 15.4 & $180 \pm 84.9$ & Chon et al. (2011) \\
\hline & $68.6-93.0$ & Flat-sheet & Micro-filtration & 15 & N.A & Radjenović et al. (2009) \\
\hline & 60.5 & Two flat-sheet & N.A & 14 & Infinite* & Radjenovic et al. (2007) \\
\hline & 52.0 & Hollow-fiber & N.A & 12 & 72 & Reif et al. (2008) \\
\hline & $64.6-92.2$ & Hollow-fiber & Ultra-filtration & 7.2 & N.A & Radjenović et al. (2009) \\
\hline & 70.1 & Hollow-fiber & N.A & N.A & N.A & Kim et al. (2007) \\
\hline Trimethoprim & $46.1-87.3$ & Flat-sheet & Micro-filtration & 15 & N.A & Radjenović et al. (2009) \\
\hline & 36.0 & Hollow-fiber & & 12 & 72 & Reif et al. (2008) \\
\hline & $25.0-70.0$ & Hollow-fiber & Ultra-filtration & 7.2 & N.A & Radjenović et al. (2009) \\
\hline Antiepileptic drugs & & & & & & \\
\hline Carbamazepine & $4.4-12.5$ & N.A & Ultra-filtration & $12-96$ & $>10$ & Clara et al. (2005) \\
\hline & 93.0 & N.A & Nano-filtration & 15.4 & $180 \pm 84.9$ & Chon et al. (2011) \\
\hline & 9.0 & Hollow-fiber & N.A & 12 & 72 & Reif et al. (2008) \\
\hline B-blockers & & & & & & \\
\hline Atenolol & 85.0 & N.A & Nano-filtration & 15.4 & $180 \pm 84.9$ & Chon et al. (2011) \\
\hline & $64.1-89.3$ & Flat-sheet & Micro-filtration & 15 & N.A & Radjenović et al. (2009) \\
\hline & 65.5 & Two flat-sheet & N.A & 14 & Infinite* & Radjenovic et al. (2007) \\
\hline & $57.0-82.0$ & Hollow-fiber & Ultra-filtration & 7.2 & N.A & Radjenović et al. (2009) \\
\hline Metoprolol & $14.9-73.8$ & Flat-sheet & Micro-filtration & 15 & N.A & Radjenović et al. (2009) \\
\hline & 58.7 & Two flat-sheet & N.A & 14 & Infinite* & Radjenovic et al. (2007) \\
\hline & $29.5-77.4$ & Hollow-fiber & Ultra-filtration & 7.2 & N.A & Radjenović et al. (2009) \\
\hline Propanolol & $65.4-89.8$ & Flat-sheet & Micro-filtration & 15 & N.A & Radjenović et al. (2009) \\
\hline & $43.1-87.9$ & Hollow-fiber & Ultra-filtration & 7.2 & N.A & Radjenović et al. (2009) \\
\hline
\end{tabular}




\begin{tabular}{|c|c|c|c|c|c|c|}
\hline \multirow[t]{2}{*}{ PPCPs } & \multirow[t]{2}{*}{ Removal \% } & \multicolumn{4}{|c|}{ Operation condition } & \multirow[t]{2}{*}{ Reference } \\
\hline & & Type of module & MBR filter & HRTs (h) & SRTs (d) & \\
\hline \multirow[t]{2}{*}{ Sotalol } & $29.0-77.2$ & Flat-sheet & Micro-filtration & 15 & N.A & Radjenović et al. (2009) \\
\hline & $5.1-55.7$ & Hollow-fiber & Ultra-filtration & 7.2 & N.A & Radjenović et al. (2009) \\
\hline \multicolumn{7}{|l|}{ Blood lipid regulators } \\
\hline \multirow[t]{3}{*}{ Bezafibrate } & $77.3-96.4$ & N.A & Ultra-filtration & $12-96$ & $>10$ & Clara et al. (2005) \\
\hline & $80.2-99.8$ & Flat-sheet & Micro-filtration & 15 & N.A & Radjenović et al. (2009) \\
\hline & 95.8 & Two flat-sheet & N.A & 14 & Infinite* & Radjenovic et al. (2007) \\
\hline Gemfibrozil & 89.6 & Two flat-sheet & N.A & 14 & Infinite* & Radjenovic et al. (2007) \\
\hline \multicolumn{7}{|l|}{ Steroids \& Hormones } \\
\hline Estriol & $>96.9$ & Hollow-fiber & N.A & N.A & N.A & Kim et al. (2007) \\
\hline Testosterone & $>83.3$ & Hollow-fiber & N.A & N.A & N.A & Kim et al. (2007) \\
\hline \multicolumn{7}{|l|}{ Stimulant } \\
\hline Caffeine & 98.9 & Hollow-fiber & N.A & N.A & N.A & Kim et al. (2007) \\
\hline \multicolumn{7}{|l|}{ Personal care products } \\
\hline Triclosan & 73.0 & Hollow-fiber & N.A & N.A & N.A & Kim et al. (2007) \\
\hline \multicolumn{7}{|l|}{ Flame retardant } \\
\hline TCEP & 0.3 & Hollow-fiber & N.A & N.A & N.A & Kim et al. (2007) \\
\hline \multicolumn{7}{|c|}{ Synthetic musks/Fragrances } \\
\hline Galaxolide (HHCB) & $84.1-91.6$ & N.A & Ultra-filtration & $12-96$ & $>10$ & Clara et al. (2005) \\
\hline Toxalide (AHTN) & $85.3-90.7$ & N.A & Ultra-filtration & $12-96$ & $>10$ & Clara et al. (2005) \\
\hline
\end{tabular}

N.A: Not available

* No discharge of sludge

\section{Conclusion}

A membrane bioreactor (MBR) is an advanced system that combines a membrane and a conventional activate sludge (CAS) system. Many studies have demonstrated that a MBR is more effective to remove CECs including PPCPs than a CAS system. More recently, MBR techniques and their integrated module have been adapted for beneficial elimination of emerging contaminants. In this study, we have aimed to review the removal efficiency of PPCPs according to MBR technologies applied with different modules. Hence, overall range of removal efficiency has been compiled for better understanding of wastewater compositions containing CECs. As a result, we came up with well-removed contaminants (e.g. acetaminophen, ibuprofen, estriol and caffeine); rarely-treated contaminants (e.g. TCEP) as well as huge range of removal efficiency (e.g. erythromycin and carbamazepine) using different types of MBRs. In general, analgesics/antiinflammatory drugs (i.e. acetaminophen and ibuprofen), steroids/hormones (i.e. estriol and testosterone) and stimulant (i.e. caffeine) seem to have higher elimination rates compare to the other PPCPs groups, whereas antimicrobial agent (i.e. TCEP) is hardly treated in a MBR system.

Removal of CECs in a MBR system can be affected by various factors such as the type of modules, SRTs, HRTs, dilution factors, and the plant configuration. Based on the findings of this study, overall removal ranges that are useful as an indicator the performance of MBR systems were compiled according to MBR modules and filters adapted. The operational conditions for removal efficiency of PPCPs in a MBR system can vary because of biological fates, physical characteristics and biodegradation of the PPCPs, which are influenced by environmental factors in the system. By increasing SRT or the sludge concentration in a MBR, more PPCPs could be efficiently eliminated from the effluent, because long SRT gives enough time that more PPCPs could bind to the sludge in MBR for the biodegradation (Spring et al., 2007). In addition, higher sludge concentration provides more adsorption sites to contaminants (Holbrook et al., 2002; Tambosi et al., 2010). Thus, relation between SRT, sludge concentration and MBR configuration could be important to develop effective a MBR system.

In this study, twenty-seven PPCPs were reviewed, even though there are numerous sort of CECs caused by both as pharmaceuticals and daily usage for personal cares. However, the result derived from this review regarding removal efficiency of PPCPs by MBR systems could provide fundamental information to assess a suitable MBR treatment systems for CECs and to investigate CECs in a MBR. Further, more detailed studies, for example, biodegradable fate of the frequently used PPCPs, combined or individual influence of operation conditions in a MBR system and catabolic enzymes through microbial communities should be needed. Studies on the removal of CECs using integrated MBRs should be carried out at laboratory scale to obtain information on their removal kinetics and mainly on the formation and degradation of by-products. Moreover, the fate and transport of CECS through the MBR treatment is required for effective elimination of CECs in MBR system.

\section{Acknowledgements}

This work was supported by Incheon National University Research Grant in 2016.

\section{References}

Archer E., Petrie B., Kasprzyk-Hordern B. and Wolfaardt G.M. (2017), The fate of pharmaceuticals and personal care products (PPCPs), endocrine disrupting contaminants (EDCs), metabolites and illicit drugs in a WWTW and environmental waters, Chemosphere, 174, 437-446.

Benjamin M.M. and Lawler D.F. (2013), Water quality engineering: Physical/chemical treatment processes, John Wiley \& Sons. 
Chang I.-S., Choo K.-H., Lee C.-H., Pek U.-H., Koh U.-C., Kim S.-W. and Koh J.-H. (1994), Application of ceramic membrane as a pretreatment in anaerobic digestion of alcohol-distillery wastes, Journal of membrane science, 90(1-2), 131-139.

Chon K., Sarp S., Lee S., Lee J.-H., Lopez-Ramirez J. and Cho J. (2011), Evaluation of a membrane bioreactor and nanofiltration for municipal wastewater reclamation: Trace contaminant control and fouling mitigation, Desalination, 272(1), 128-134.

Clara M., Strenn B., Gans O., Martinez E., Kreuzinger N. and Kroiss H. (2005), Removal of selected pharmaceuticals, fragrances and endocrine disrupting compounds in a membrane bioreactor and conventional wastewater treatment plants, Water research, 39(19), 4797-4807.

Dotan P., Godinger T., Odeh W., Groisman L., Al-Khateeb N., Rabbo A.A., Tal A. and Arnon S. (2016), Occurrence and fate of endocrine disrupting compounds in wastewater treatment plants in Israel and the Palestinian West Bank, Chemosphere, 155, 86-93.

Ellis J.B. (2006), Pharmaceutical and personal care products (PPCPs) in urban receiving waters, Environmental pollution, 144(1), 184-189.

Ersu C. and Ong S. (2008), Treatment of wastewater containing phenol using a tubular ceramic membrane bioreactor, Environmental technology, 29(2), 225-234.

Eskenazi B., Rauch S.A., Tenerelli R., Huen K., Holland N.T., Lustig R.H., Kogut K., Bradman A., Sjödin A. and Harley K.G. (2017), In utero and childhood DDT, DDE, PBDE and PCBs exposure and sex hormones in adolescent boys: The CHAMACOS study, International journal of hygiene and environmental health, 220(2), 364-372.

Esplugas S., Bila D.M., Krause L.G.T. and Dezotti M. (2007), Ozonation and advanced oxidation technologies to remove endocrine disrupting chemicals (EDCs) and pharmaceuticals and personal care products (PPCPs) in water effluents, Journal of Hazardous Materials, 149(3), 631-642.

Fisch K., Waniek J.J. and Schulz-Bull D.E. (2017), Occurrence of pharmaceuticals and UV-filters in riverine run-offs and waters of the German Baltic Sea, Marine pollution bulletin, 124(1), 388-399.

Fisch K., Waniek J.J. and Schulz-Bull D.E. (2017). Occurrence of PPCPs in Pearl River Estuary and South China Sea, EGU General Assembly Conference Abstracts.

Ghyoot W. and Verstraete W. (1997), Coupling membrane filtration to anaerobic primary sludge digestion, Environmental technology, 18(6), 569-580.

Giulivo M., de Alda M.L., Capri E. and Barceló D. (2016), Human exposure to endocrine disrupting compounds: Their role in reproductive systems, metabolic syndrome and breast cancer, A review, Environmental research, 151, 251-264.

Gros M., Petrović M., Ginebreda A. and Barceló D. (2010), Removal of pharmaceuticals during wastewater treatment and environmental risk assessment using hazard indexes, Environment international, 36(1), 15-26.

Guo W.Q., Cao H.O., Zhou X.J. and Yin R.L. (2014). Occurrence and Treatment of Pharmaceuticals and Personal Care Products in Surface Water around the Global Region, Applied Mechanics and Materials.

Hai F.I., Tessmer K., Nguyen L.N., Kang J., Price W.E. and Nghiem L.D. (2011), Removal of micropollutants by membrane bioreactor under temperature variation, Journal of membrane science, 383(1), 144-151.

Hashim N.H., Nasir M.H. and Ramlee M.S. (2016). Emerging Pollutant of Concern: Occurrence of Pharmaceutical Compounds in Asia with Particular Preference to Southeast Asia Countries, MATEC Web of Conferences.

Holbrook R.D., Novak J.T., Grizzard T.J. and Love N.G. (2002), Estrogen receptor agonist fate during wastewater and biosolids treatment processes: A mass balance analysis, Environmental Science \& Technology, 36(21), 4533-4539.

Holtz S. (2006), There is No away: Pharmaceuticals, Personal Care Products and Endocrine-disrupting Substances: Emerging Contaminants Detected in Water, Canadian Institute for Environmental Law and Policy.

Howell J.A. (2004), Future of membranes and membrane reactors in green technologies and for water reuse, Desalination, 162, 1-11.

Imasaka T., Kanekuni N., So H. and Yoshino S. (1989), Cross-flow filtration of methane fermentation broth by ceramic membranes, Journal of fermentation and bioengineering, 68(3), 200-206.

Jefferson B., Laine A., Judd S. and Stephenson T. (2000), Membrane bioreactors and their role in wastewater reuse, Water Science and Technology, 41(1), 197-204.

Jiang J.-Q., Zhou Z. and Sharma V. (2013), Occurrence, transportation, monitoring and treatment of emerging micro-pollutants in waste water-a review from global views, Microchemical Journal, 110, 292-300.

K'oreje K., Vergeynst L., Ombaka D., De Wispelaere P., Okoth M., Van Langenhove H. and Demeestere K. (2016), Occurrence patterns of pharmaceutical residues in wastewater, surface water and groundwater of Nairobi and Kisumu city, Kenya, Chemosphere, 149, 238-244.

Kasprzyk-Hordern B., Dinsdale R.M. and Guwy A.J. (2009), The removal of pharmaceuticals, personal care products, endocrine disruptors and illicit drugs during wastewater treatment and its impact on the quality of receiving waters, Water research, 43(2), 363-380.

Kim I. and Tanaka H. (2009), Photodegradation characteristics of PPCPs in water with UV treatment, Environment International, 35(5), 793-802.

Kim J.-O. and Jung J.-T. (2007), Performance of membranecoupled organic acid fermentor for the resources recovery form municipal sewage sludge, Water science and technology, 55(10), 245-252.

Kim S.D., Cho J., Kim I.S., Vanderford B.J. and Snyder S.A. (2007), Occurrence and removal of pharmaceuticals and endocrine disruptors in South Korean surface, drinking, and waste waters, Water research, 41(5), 1013-1021.

Krogh J., Lyons S. and Lowe C.J. (2017), Pharmaceuticals and personal care products in municipal wastewater and the marine receiving environment near Victoria Canada, Frontiers in Marine Science, 4, 415.

Kumar A. and Xagoraraki I. (2010), Pharmaceuticals, personal care products and endocrine-disrupting chemicals in US surface and finished drinking waters: a proposed ranking system, Science of the Total Environment, 408(23), 59725989.

Kumar R.V., Ghoshal A.K. and Pugazhenthi G. (2015), Elaboration of novel tubular ceramic membrane from inexpensive raw 
materials by extrusion method and its performance in microfiltration of synthetic oily wastewater treatment, Journal of Membrane Science, 490, 92-102.

Kwon Y. and Lee D.G. (2017), Occurrence of pharmaceutical and personal care products (PPCPS) in the african aquatic environment: a brief review for the future of environment, Fresenius Environmental Bulletin, 26(10), 5971-5979.

Lapworth D., Baran N., Stuart M. and Ward R. (2012), Emerging organic contaminants in groundwater: a review of sources, fate and occurrence, Environmental pollution, 163, 287-303.

Lee S.-J., Dilaver M., Park P.-K. and Kim J.-H. (2013), Comparative analysis of fouling characteristics of ceramic and polymeric microfiltration membranes using filtration models, Journal of Membrane Science, 432, 97-105.

Leyva-Díaz J., Martín-Pascual J., González-López J., Hontoria E. and Poyatos J. (2013), Effects of scale-up on a hybrid moving bed biofilm reactor-membrane bioreactor for treating urban wastewater, Chemical Engineering Science, 104, 808-816.

Lin H., Peng W., Zhang M., Chen J., Hong H. and Zhang Y. (2013), A review on anaerobic membrane bioreactors: applications, membrane fouling and future perspectives, Desalination, 314, 169-188.

Liu J.-L. and Wong M.-H. (2013), Pharmaceuticals and personal care products (PPCPs): a review on environmental contamination in China, Environment international, 59, 208224.

Lu Y., Yuan T., Wang W. and Kannan K. (2011), Concentrations and assessment of exposure to siloxanes and synthetic musks in personal care products from China, Environmental pollution, 159(12), 3522-3528.

Mandaric L., Diamantini E., Stella E., Cano-Paoli K., Valle-Sistac J., Molins-Delgado D., Bellin A., Chiogna G., Majone B. and DiazCruz M.S. (2017), Contamination sources and distribution patterns of pharmaceuticals and personal care products in Alpine rivers strongly affected by tourism, Science of the Total Environment, 590, 484-494.

Marrot B., Barrios-Martinez A., Moulin P. and Roche N. (2004), Industrial wastewater treatment in a membrane bioreactor: a review, Environmental Progress \& Sustainable Energy, 23(1), 59-68.

Mascolo G., Laera G., Pollice A., Cassano D., Pinto A., Salerno C. and Lopez A. (2010), Effective organics degradation from pharmaceutical wastewater by an integrated process including membrane bioreactor and ozonation, Chemosphere, 78(9), 1100-1109.

Meffe R. and de Bustamante I. (2014), Emerging organic contaminants in surface water and groundwater: a first overview of the situation in Italy, Science of the Total Environment, 481, 280-295.

Nath K. (2017), Membrane separation processes, PHI Learning Pvt. Ltd.

Neoh C.H., Noor Z.Z., Mutamim N.S.A. and Lim C.K. (2016), Green technology in wastewater treatment technologies: integration of membrane bioreactor with various wastewater treatment systems, Chemical engineering journal, 283, 582-594.
Pan B., Ning P. and Xing B. (2009), Part V-sorption of pharmaceuticals and personal care products, Environmental Science and Pollution Research, 16(1), 106-116.

Petrie B., Barden R. and Kasprzyk-Hordern B. (2015), A review on emerging contaminants in wastewaters and the environment: current knowledge, understudied areas and recommendations for future monitoring, Water Research, 72, 3-27.

Radjenovic J., Petrovic M. and Barceló D. (2007), Analysis of pharmaceuticals in wastewater and removal using a membrane bioreactor, Analytical and bioanalytical chemistry, 387(4), 1365-1377.

Radjenović J., Petrović M. and Barceló D. (2009), Fate and distribution of pharmaceuticals in wastewater and sewage sludge of the conventional activated sludge (CAS) and advanced membrane bioreactor (MBR) treatment, Water research, 43(3), 831-841.

Reif R., Suárez S., Omil F. and Lema J. (2008), Fate of pharmaceuticals and cosmetic ingredients during the operation of a MBR treating sewage, Desalination, 221(1-3), 511-517.

Schäfer A., Mastrup M. and Jensen R.L. (2002), Particle interactions and removal of trace contaminants from water and wastewaters, Desalination, 147(1-3), 243-250.

Shamsuddin N., Das D.B. and Starov V.M. (2015), Filtration of natural organic matter using ultrafiltration membranes for drinking water purposes: circular cross-flow compared with stirred dead end flow, Chemical Engineering Journal, 276, 331-339.

Shariati F.P., Mehrnia M.R., Salmasi B.M., Heran M., Wisniewski C. and Sarrafzadeh M.H. (2010), Membrane bioreactor for treatment of pharmaceutical wastewater containing acetaminophen, Desalination, 250(2), 798-800.

Shen L.-g., Lei Q., Chen J.-R., Hong H.-C., He Y.-M. and Lin H.-J. (2015), Membrane fouling in a submerged membrane bioreactor: impacts of floc size, Chemical Engineering Journal, 269, 328-334.

Spring A., Bagley D.M., Andrews R.C., Lemanik S. and Yang P. (2007), Removal of endocrine disrupting compounds using a membrane bioreactor and disinfection, Journal of Environmental Engineering and Science, 6(2), 131-137.

Stuart M., Lapworth D., Crane E. and Hart A. (2012), Review of risk from potential emerging contaminants in UK groundwater, Science of the Total Environment, 416, 1-21.

Subedi B., Codru N., Dziewulski D.M., Wilson L.R., Xue J., Yun S., Braun-Howland E., Minihane C. and Kannan K. (2015), A pilot study on the assessment of trace organic contaminants including pharmaceuticals and personal care products from on-site wastewater treatment systems along Skaneateles Lake in New York State, USA, Water research, 72, 28-39.

Sui Q., Zhao W., Cao X., Lu S., Qiu Z., Gu X. and Yu G. (2017), Pharmaceuticals and personal care products in the leachates from a typical landfill reservoir of municipal solid waste in Shanghai, China: Occurrence and removal by a full-scale membrane bioreactor, Journal of hazardous materials, 323, 99-108.

Tambosi J.L., de Sena R.F., Favier M., Gebhardt W., José H.J., Schröder H.F. and Moreira R.d.F.P.M. (2010), Removal of pharmaceutical compounds in membrane bioreactors (MBR) applying submerged membranes, Desalination, 261(1), 148156. 
Tan J.-M., Qiu G. and Ting Y.-P. (2015), Osmotic membrane bioreactor for municipal wastewater treatment and the effects of silver nanoparticles on system performance, Journal of Cleaner Production, 88, 146-151.

Tan S.P., Kong H.F., Bashir M.J., Lo P.K., Ho C.-D. and Ng C.A. (2017), Treatment of palm oil mill effluent using combination system of microbial fuel cell and anaerobic membrane bioreactor, Bioresource Technology, 245, 916-924.

Tijani J.O., Fatoba O.O., Babajide O.O. and Petrik L.F. (2016), Pharmaceuticals, endocrine disruptors, personal care products, nanomaterials and perfluorinated pollutants: a review, Environmental chemistry letters, 14(1), 27-49.

Tiwari B., Sellamuthu B., Ouarda Y., Drogui P., Tyagi R.D. and Buelna G. (2016), Review on fate and mechanism of removal of pharmaceutical pollutants from wastewater using biological approach, Bioresource technology.

Visvanathan C., Aim R.B. and Parameshwaran K. (2000), Membrane separation bioreactors for wastewater treatment, Critical reviews in environmental science and technology, 30(1), 1-48.

Wang X., Chen Y., Yuan B., Li X. and Ren Y. (2014), Impacts of sludge retention time on sludge characteristics and membrane fouling in a submerged osmotic membrane bioreactor, Bioresource technology, 161, 340-347.

Wilkinson J.L., Hooda P.S., Barker J., Barton S. and Swinden J. (2016), Ecotoxic pharmaceuticals, personal care products, and other emerging contaminants: $A$ review of environmental, receptor-mediated, developmental, and epigenetic toxicity with discussion of proposed toxicity to humans, Critical Reviews in Environmental Science and Technology, 46(4), 336-381.

Yamamoto K., Hiasa M., Mahmood T. and Matsuo T. (1989), Direct solid-liquid separation using hollow fiber membrane in an activated sludge aeration tank, Water Science and Technology, 21(4-5), 43-54.

Yang Y., Ok Y.S., Kim K.-H., Kwon E.E. and Tsang Y.F. (2017), Occurrences and removal of pharmaceuticals and personal care products (PPCPs) in drinking water and water/sewage treatment plants: A review, Science of the Total Environment, 596, 303-320.

Ying G., Kookana R. and Waite T. (2004), Endocrine disrupting chemicals (EDCs) and pharmaceuticals and personal care products (PPCPs) in reclaimned water in Australia.

Yoon S.-H. (2015), Membrane bioreactor processes: Principles and applications, CRC press. 